\title{
Desain dan Simulasi Battery Charger Metode CC- CV (Constant Current-Constant Voltage) dengan Kontrol Logika Fuzzy Menggunakan MATLAB
}

\author{
Irianto $^{1}$, Diah Septi Yanaratri ${ }^{2}$, dan Faris Rahmatullah ${ }^{3}$ \\ 1,2,3 Politeknik Elektronika Negeri Surabaya \\ Jl. Raya ITS, Keputih Kec. Sukolilo Kota Surabaya Jawa Timur, 60111 \\ e-mail: farisrahmatullah@pe.student.pens.ac.id
}

\begin{abstract}
Abstrak - Baterai merupakan salah satu sistem penyimpanan energi listrik. Namun, dalam pengisiannya rentan mengalami kerusakan. Kerusakan pada baterai sering terjadi ketika dilakukan pengisian daya yang berlebih (over charging). Waktu pengisian baterai juga menjadi faktor yang perlu diperhatikan dalam pengisian daya. Oleh karena itu, pengisian daya baterai yang efisien menjadi penting dan sangat perlu dilakukan untuk menghindari terjadinya kerusakan. Sistem charging pada baterai disini dengan metode constant current-constant voltage (CC-CV) menggunakan dua buah kontrol logika fuzzy. Metode charging CC-CV digunakan untuk memaksimalkan daya charging dengan waktu yang singkat serta mencegah terjadinya over charging pada baterai. Kontrol logika fuzzy pertama dan kedua digunakan untuk mengatur duty cycle agar arus konstan dan tegangan konstan. Dari hasil simulasi menggunakan metode CC-CV ketika kondisi CC diperoleh nilai arus sebesar 3.3A pada duty cycle $42.6 \%$ dan terjadi transisi menuju kondisi CV ketika state of charge (SoC) $80.02 \%$ dengan nilai tegangan sebesar 14.4 V pada duty cycle 41.2\%. Pengisian daya dan peningkatan SoC pada metode CC-CV lebih cepat 0.15 detik terhadap metode $\mathrm{CC}$ dan 0.25 detik terhadap metode $\mathrm{CV}$.
\end{abstract}

\section{Kata kunci: Battery Charging, Buck Converter, Logika Fuzzy, Constant Current, Constant Voltage}

\begin{abstract}
Battery is one of the electrical energy storage systems. However, in its charging process is prone to damage. Damage to the battery often occurs due to overcharging. Time is one important factor to consider in charging. Therefore, an efficient charging system is important and indispensable to avoid damage. The method used in this charging system is the constant current-constant voltage (CC-CV) method with two fuzzy logic controls used to calculate the duty cycle of converter. CC-CV charging method is used to maximize charging power with a short amount of time and prevent over charging on the battery. The fuzzy logic controls are used to set constant current and constant voltage. From the simulation results using $C C-C V$ method, in $C C$ state the current value obtained is $3.3 A$ on duty cycle $42.6 \%$ and the transition to CV state occurs at state of charge (SoC) $80.02 \%$ with voltage value of $14.4 \mathrm{~V}$ at duty cycle $41.2 \%$. The increase of SoC percentage using CC-CV method is 0.15 seconds faster than CC method while compared to CV method is 0.25 seconds faster.
\end{abstract}

Keywords: Battery Charging, Buck Converter, Fuzzy Logic, Constant Current, Constant Voltage

\section{PENDAHULUAN}

Energi listrik merupakan salah satu kebutuhan manusia yang sangat penting dan vital yang tidak dapat dilepaskan dari keperluan sehari-hari. Kesadaran akan energi di seluruh dunia tentang isu lingkungan telah mengakibatkan pentingnya peningkatan pengembangan sistem penyimpanan energi. Untuk mendukung penyedia energi tersebut, penyimpanan energi menjadi sangat penting untuk menyediakan pasokan yang handal dan kontinyu dalam waktu yang relatif lama, salah satunya adalah baterai.

Baterai adalah salah satu sistem penyimpanan energi yang paling menarik karena efisiensi tinggi dan polusi rendah [1]. Namun dalam pemakaiannya baterai mudah mengalami kerusakan dan tidak dapat diketahui apakah masih dalam keadaan baik atau sudah rusak. Kelebihan pengisian daya dan pemakaian berlebihan akan mengurangi masa pakai baterai dan akan mengakibatkan kerusakan ekstrem pada baterai [2].

Konverter DC-DC adalah sirkuit elektronika daya yang mengubah tegangan DC ke tegangan DC dengan nilai yang berbeda, sesuai dengan jenis dan pengaturan output [3]. Konverter DC-DC melakukan dua fungsi yakni mengubah tingkat tegangan output (meningkat atau berkurang) dan memberikan tegangan beban konstan [4]. Tegangan keluaran dilakukan dengan pengaturan lamanya waktu penghubungan menggunakan switch antara sisi keluaran dan sisi masukan pada rangkaian yang sama.

Buck converter merupakan rangkaian elektronika daya yang berfungsi menurunkan tegangan DC. Pemilihan buck converter didasarkan pada efisiensi yang tinggi dalam perubahan daya serta rangkaian yang sederhana [5]. 
Biasanya digunakan untuk mengontrol tegangan keluaran yang sesuai untuk beberapa aplikasi seperti charging baterai dan kontrol motor DC. Sistem kontrol yang akan digunakan ialah Fuzzy Logic Controller untuk mengatur tegangan charging tetap konstan.

Pada fuzzy logic controller digambarkan secara sederhana kesimpulan dari informasi yang samar-samar. Terdapat aturan yang berasal dari data observasional memberikan pengetahuan tentang sistem yang disimulasikan [6]. Kehandalan fuzzy logic tidak bergantung pada model matematis sistem yang dikendalikan namun pada kegiatan percobaan dan pengalaman [7].

\section{STUDI PUSTAKA}

\section{A. Full Wave Rectifier}

Full Wave Rectifier digunakan untuk menghasilkan tegangan atau arus DC yang murni. Output dari full wave rectifier secara inheren memiliki lebih sedikit riak/ripple daripada half wave rectifier [3].

$$
\begin{gathered}
V_{i n_{(\max )}}=\operatorname{Vin}_{(\text {rms })} \times \sqrt{2} \\
\Delta \mathrm{Vo}=1 \% \times \operatorname{Vin}_{(\max )} \\
V o_{(d c)}=V i_{(\max )}-\frac{\Delta \mathrm{Vo}}{2} \\
\mathrm{C}=\frac{\operatorname{Vin}_{(\max )}}{2 \times f \times R \times \Delta \mathrm{Vo}}
\end{gathered}
$$

Keterangan:

$$
\begin{array}{ll}
V o_{(d c)} & =\text { Tegangan Output DC (V) } \\
V i n_{(\max )} & =\text { Tegangan Input RMS (A) } \\
\Delta \mathrm{Vo} & =\text { Ripple Tegangan Output } \\
\mathrm{C} & =\text { Kapasitansi (F) }
\end{array}
$$

Masukan penyarah berasal dari transformator $24 \mathrm{~V}$ untuk menghasilkan tegangan keluaran sebesar 33.7 VDC. Penggunaan persamaan 1,2,3 dan 4 dilakukan sebagai perhitungan untuk mendapatkan keluaran penyearah yang sesuai.

\section{B. DC-DC Buck Converter}

DC-DC buck converter digunakan untuk menghasilkan jumlah tegangan output yang rendah dari jumlah tegangan input yang tinggi [8]. Terdiri dari beban resistor (R), induktor (L), kapasitor (C), ultra fast diode, dan MOSFET transistor sebagai switch.

$$
\begin{gathered}
D=\frac{V_{o}}{V_{S}} \\
R=\frac{V_{o}}{I_{o}} \\
L=\left(\frac{1}{f}\right) \times\left(V_{s}-V_{o}\right) \times\left(\frac{V_{o}}{V_{S}}\right) \times\left(\frac{1}{\Delta I_{L}}\right) \\
C=\frac{1-D}{8 \times L \times\left(\frac{\Delta V_{o}}{V_{o}}\right) \times f^{2}}
\end{gathered}
$$

$$
\begin{aligned}
& \text { Keterangan: } \\
& D \\
& R
\end{aligned}
$$

Perancangan desain dari buck converter meliputi besarnya duty cycle yang diberikan untuk menghasilkan keluaran yang sesuai. Untuk mengurangi riak/ripple tegangan, filter yang terbuat dari kapasitor ditambahkan ke output konverter dan input.

Tabel 1. Spesifikasi DC-DC Buck Converter

\begin{tabular}{lc}
\hline \multicolumn{1}{c}{ Parameter } & Nilai \\
\hline Tegangan Input (Vin) & $33.77 \mathrm{~V}$ \\
Arus Input (lin) & $3 \mathrm{~A}$ \\
Tegangan Output (Vo) & $14.4 \mathrm{~V}$ \\
Arus Output (Io) & $3.6 \mathrm{~A}$ \\
Frekuensi (fs) & $40 \mathrm{kHz}$ \\
Resistansi (R) & $4 \Omega$ \\
Induktansi (L) & $268.8 \mu \mathrm{H}$ \\
Capacitance (C) & $166.83 \mu \mathrm{F}$ \\
\hline
\end{tabular}

Pada tabel 1. menunjukkan besar nilai masing-masing komponen pada sistem untuk menghasilkan tegangan keluaran sebesar $14.4 \mathrm{~V}$.

\section{Fuzzy Logic Controller}

Logika Fuzzy menggabungkan perhitungan matematis dan algoritma. Dalam memproses setiap masukan, metode fuzzy menggunakan range-to-point control. Setiap parameter (input/output) diklasifikasikan dalam variabel linguistik [7].

Metode Kontrol Logika Fuzzy yang digunakan pada sistem ini ialah Metode Mamdani. Metode mamdani lebih intuitif, sangat fleksibel terhadap data dan sudah digunakan oleh banyak pihak. Kontrol Logika Fuzzy digunakan untuk mengendalikan pembangkitan PWM yang berfungsi untuk mengontrol tegangan output Buck Converter agar tetap konstan.

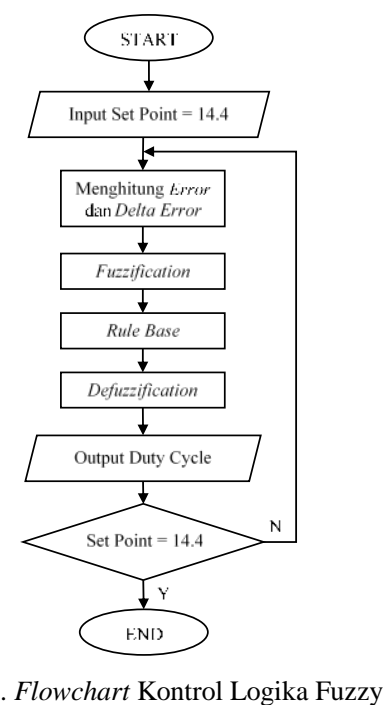

Pada Gambar 1. merupakan flowchart Kontrol Logika Fuzzy dimana parameter yang akan digunakan sebagai input ialah parameter tegangan dan arus. Parameter ini akan 
dikonversikan menjadi dua variabel fuzzy yakni $\operatorname{error}(e)$ dan delta error (de).

Kedua variabel ini nantinya akan di olah melalui Fuzzyfication, Fuzzy Inference System serta Defuzzification yang akan menghasilkan output berupa besaran duty ratio untuk pembangkitan PWM sebagai switching dari Buck Converter. Fuzzification merupakan transformasi domain dari crisp menjadi input fuzzy [9].

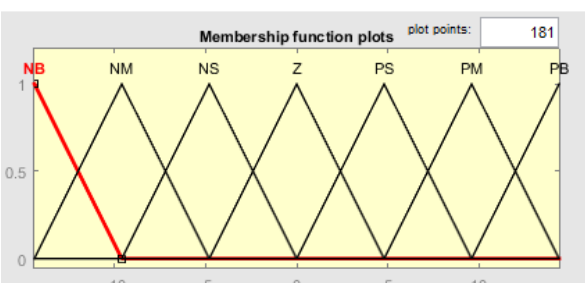

Gambar 2. Fungsi Keanggotaan Input Fuzzy Variabel Error

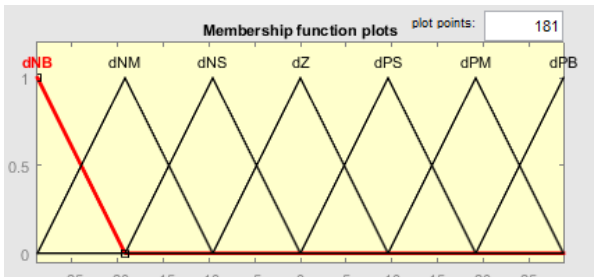

Gambar 3. Fungsi Keanggotaan Input Fuzzy Variabel Delta Error

Gambar 2. menunjukkan fungsi keanggotaan variabel error dengan rentang -14.4 sampai 14.4. Pada gambar 3 . menunjukkan fungsi keanggotaan variabel delta error dengan rentang -28.8 sampai 28.8 .

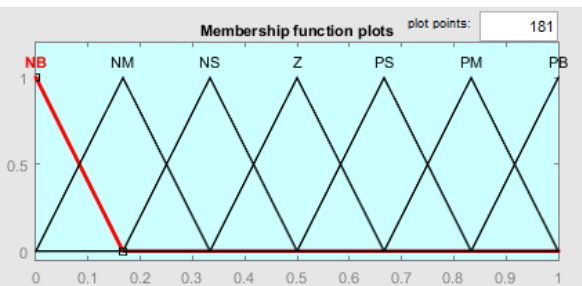

Gambar 4. Fungsi Keanggotaan Output Fuzzy Variabel Duty Cycle

Gambar 4. merupakan fungsi keanggotaan output fuzzy yakni berupa duty cycle dengan rentang 0 sampai 1 . Keluaran dari fuzzifikasi akan diolah fuzzy inference system dengan mempertimbangkan rule based yang telah ditentukan.

Tabel 2. Fuzzy Rule Based

\begin{tabular}{cccccccc}
\hline $\mathbf{E}$ & NB & NM & NS & ZO & PS & PM & PB \\
\hline NB & NB & NB & NB & NB & NM & NS & ZO \\
NM & NB & NB & NB & NM & NS & ZO & PS \\
NS & NB & NB & NM & NS & ZO & PS & PM \\
ZO & NB & NM & NS & ZO & PS & PM & PB \\
PS & NM & NS & ZO & PS & PM & PB & PB \\
PM & NS & ZO & PS & PM & PB & PB & PB \\
PB & ZO & PS & PM & PB & PB & PB & PB \\
\hline
\end{tabular}

Tabel 2. Merupakan aturan dasar yang menentukan aksi kontrol untuk menentukan besaran output yakni duty cycle.
Keluaran dari fuzzy inference system akan diolah sebagai input defuzzifikasi yang diekspresikan dalam bentuk fuzzy set ke bilangan ril.

Defuzzifikasi ialah proses mengkonversi nilai fuzzy output kembali menjadi data keluaran tegas (crisp output) atau keluaran klasik kepada objek kontrol [10]. Metode defuzzification yang digunakan ialah Metode Centroid. Dimana output solusi crisp diperoleh dengan cara mengambil titik pusat. Output berupa besar nilai duty cycle $0-1$ untuk menjaga tegangan output tetap konstan.

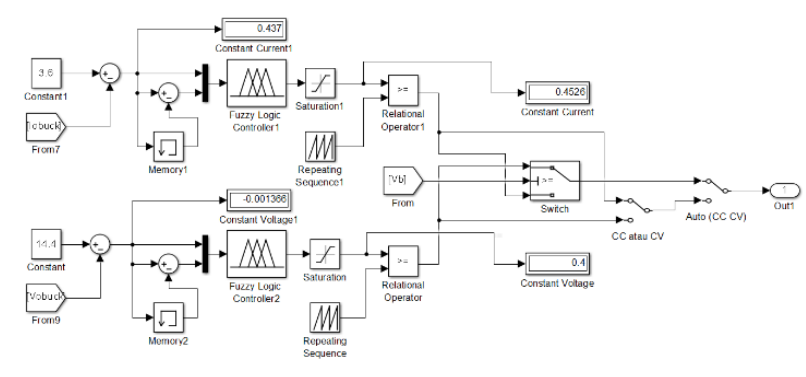

Gambar 5. Rangkaian Kontrol Logika Fuzzy

Terlihat pada gambar 5. ialah rangkaian kontrol dengan parameter masukan tegangan dan arus. Kedua parameter ini diolah menjadi dua variabel fuzzy (error dan delta error) untuk di proses menjadi keluaran berupa nilai duty cycle. Terdapat switch sebagai pergantian dari proses charging constant current (CC) menuju constant voltage (CV).

\section{METODE}

Sistem dialiri sumber sebesar 220 VAC yang masuk menuju full wave rectifier untuk disearahkan menjadi tegangan DC. Keluaran penyearah menjadi input buck converter untuk dapat distabilkan dan diturunkan menjadi 14.4 VDC yakni sebagai tegangan charging.

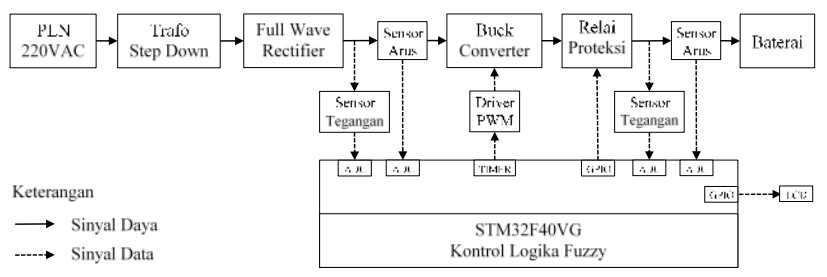

Gambar 6. Skema Sistem

Pada gambar 6. Kontrol logika fuzzy mendapat input dari parameter tegangan dan arus untuk dapat diolah sebagai masukan. Hasil keluarannya berupa besar duty cycle yang diberikan melalui driver PWM sebagai switching untuk menjaga keluaran buck converter.

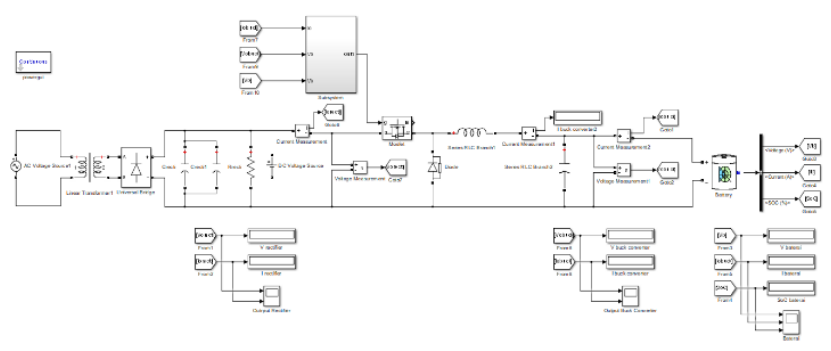

Gambar 7. Rangkaian Simulasi MATLAB 
Output dari buck converter sebagai tegangan charging pada baterai. Pada gambar 7. terlihat rangkaian simulink pada MATLAB dimana menggambarkan keseluruhan sistem. Input fuzzy yakni tegangan, arus dan state of charge didapat dari parameter output pada baterai.

\section{HASIL DAN PEMBAHASAN}

Simulasi dilakukan dengan running time selama 3 detik secara continuous. Pada gambar 7. terlihat respon keluaran pada sistem open loop. Besar duty cycle mempengaruhi besar kecilnya tegangan keluaran dari buck converter. Semakin besar duty cycle yang diberikan, semakin besar tegangan pada keluaran buck converter.

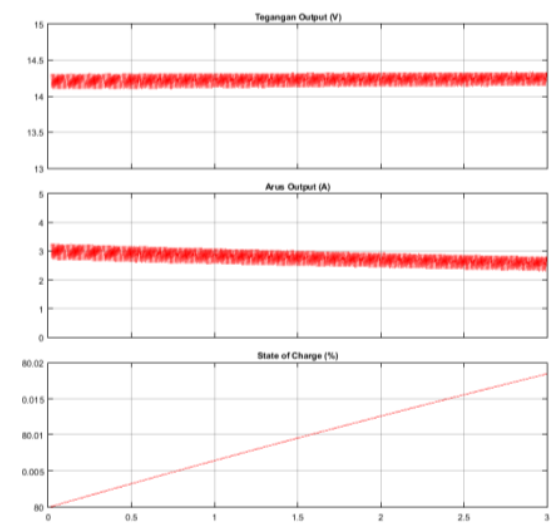

Gambar 8. Respon Tegangan, Arus, dan SoC dalam Kondisi Open Loop

Tabel 3. SoC, Tegangan dan Arus (open loop)

\begin{tabular}{ccc}
\hline SoC (\%) & Tegangan $(\mathbf{V})$ & Arus $(\mathbf{A})$ \\
\hline 80 & 14.25 & 3 \\
80.005 & 14.25 & 2.9 \\
80.01 & 14.25 & 2.8 \\
80.015 & 14.25 & 2.7 \\
80.018 & 14.25 & 2.6 \\
\hline
\end{tabular}

Terdapat data keluaran buck converter atau masukan baterai hasil pengujian pada tabel 3. Terlihat jika arus terus menurun, hal ini disebabkan karena duty cycle pada kondisi open loop bernilai konstan atau tanpa kontrol. Maka tegangan keluaran bernilai konstan dan arus akan menurun sesuai karakteristik charging baterai. Pada gambar 9. menunjukkan respon output ketika kondisi constant current. Terjadi peningkatan nilai tegangan seiring kenaikan state of charge (SoC).

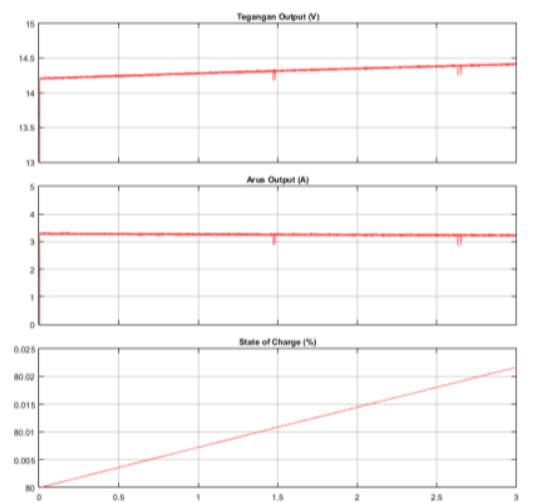

Gambar 9. Respon Tegangan, Arus, dan SoC dalam Kondisi Constant Current
Tabel 4. SoC, Tegangan dan Arus (constant current)

\begin{tabular}{ccc}
\hline SoC $(\%)$ & Tegangan $(\mathbf{V})$ & Arus $(\mathbf{A})$ \\
\hline 80 & 14.2 & 3.2 \\
80.005 & 14.25 & 3.2 \\
80.01 & 14.3 & 3.2 \\
80.015 & 14.35 & 3.2 \\
80.02 & 14.4 & 3.2 \\
80.022 & 14.42 & 3.2 \\
\hline
\end{tabular}

Data hasil penguijan kondisi over current ditampilkan pada tabel 4. Peningkatan nilai tegangan disebabkan oleh karakteristik dari charging baterai. Pada kondisi ini, kontrol digunakan untuk mengatur besar nilai arus konstan 3.3 A. Maka ketika arus charging konstan, tegangan akan terus naik walaupun sudah mencapai tegangan maksimal. Hal ini berbahaya karena bisa menyebabkan over voltage pada baterai dan menyebabkan kerusakan pada baterai.

Respon kondisi constant voltage terlihat pada gambar 10 . Terjadi penurunan pada nilai arus charging seiring peningkatan nilai SoC. Tegangan akan tetap bernilai konstan 14.2 $\mathrm{V}$ walaupun arus terus menurun.
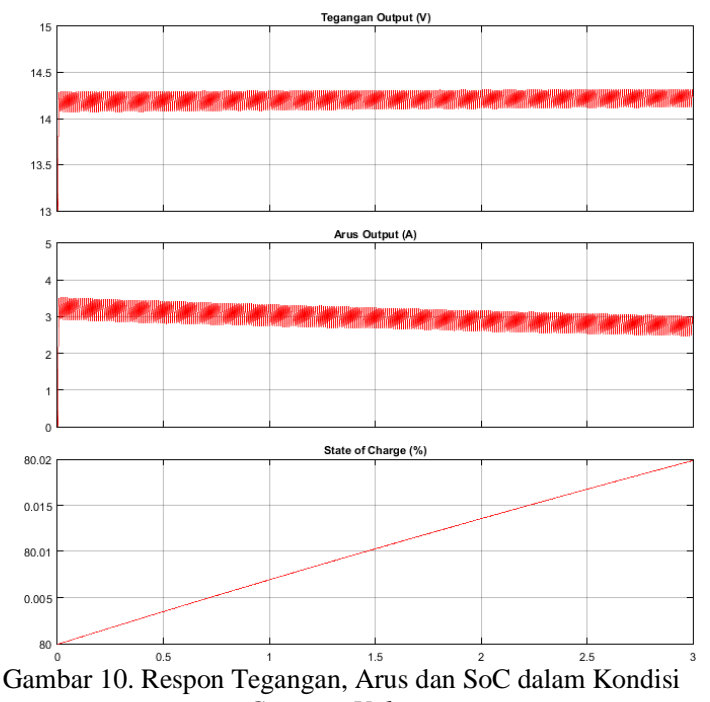
Constant Voltage

Tabel 5. SoC, Tegangan dan Arus (constant voltage)

\begin{tabular}{ccc}
\hline SoC (\%) & Tegangan $(\mathbf{V})$ & Arus (A) \\
\hline 80 & 14.25 & 3.4 \\
80.005 & 14.25 & 3.2 \\
80.01 & 14.25 & 3 \\
80.015 & 14.25 & 2.8 \\
80.02 & 14.25 & 2.6 \\
\hline
\end{tabular}

Terjadi penurunan nilai arus pada respon maupun data yang terlihat pada tabel 5. Dimana hal ini disebabkan karena kontrol fuzzy hanya mengatur tegangan bukan arus. Maka arus secara karakteristik akan menurun. Metode charging ini jarang digunakan karena efektifitas yang kurang baik dan waktu charging yang cukup lama.

Pada gambar 11. Terlihat respon output pada kondisi charging dengan constant current-constant voltage. Sistem ini menggunakan set point sebesar $3.6 \mathrm{~A}$ pada constant current dan $14.4 \mathrm{~V}$ pada constant voltage sebagai daya charging pada baterai. Transisi CC menuju CV terjadi ketika tegangan mencapai tegangan maksimum $14.4 \mathrm{~V}$ yakni pada SoC $80.02 \%$. Dimana kedua kondisi ini dilakukan menggunakan dua sistem kontrol terpisah. 


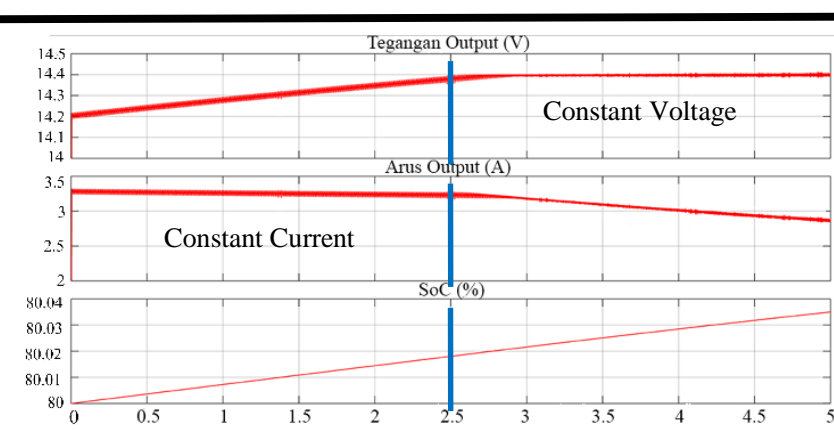

Gambar 11. Respon Tegangan, Arus dan SoC dalam Kondisi CC-CV (Constant Current-Constant Voltage)

Tabel 6. SoC, Tegangan dan Arus $(C C-C V)$

\begin{tabular}{ccc}
\hline SoC $(\%)$ & Tegangan $(\mathbf{V})$ & Arus $(\mathbf{A})$ \\
\hline 80 & 14.2 & 3.3 \\
80.005 & 14.25 & 3.3 \\
80.01 & 14.3 & 3.3 \\
80.015 & 14.35 & 3.3 \\
80.02 & 14.4 & 3.3 \\
80.025 & 14.4 & 3.16 \\
80.03 & 14.4 & 3 \\
80.035 & 14.4 & 2.66 \\
\hline
\end{tabular}

Terjadi transisi dari metode charging constant current menjadi constant voltage ketika tegangan mencapai $14.4 \mathrm{~V}$ atau tegangan maksimal pada baterai. Pada tabel 6 . Terlihat transisi terjadi ketika tegangan bernilai $14.4 \mathrm{~V}$ dan arus 3.3 A. State of charge (SoC) akan terus meningkat atau mengisi daya seiring berjalannya transisi maupun dia kedua kondisi. Transisi di tegangan maksimal baterai dilakukan untuk menghindari terjadinya over voltage pada baterai. Constant current-constant voltage dilakukan untuk memaksimalkan daya dan meminimalisir waktu pada charging baterai. Ripple yang dialami disebabkan karena masukan dari sistem berupa tegangan AC namun masih tahap wajar.

\section{KESIMPULAN}

Pada simulasi ini didapatkan hasil ketika dilakukan dalam kondisi open loop tegangan keluaran sebesar $14.25 \mathrm{~V}$ konstan dengan arus sebesar 3 A. Pada metode charging CC-CV diperoleh nilai arus sebesar 3.3 A pada duty cycle $42.6 \%$ ketika kondisi CC dan nilai tegangan sebesar $14.4 \mathrm{~V}$ pada duty cycle $41.2 \%$ ketika kondisi CV. Pengisian daya dan peningkatan SoC pada kondisi CC-CV lebih cepat 0.15 detik jika dibandingkan dengan constant current dan 0.25 detik dengan constant voltage.

\section{REFERENSI}

[1] M. Charkhgard dan M. Farrokhi, "State-of-Charge Estimation for Lithium-Ion Batteries Using Neural Networks and EKF," IEEE Trans. Ind. Electron., vol. 57, no. 12, hlm. 4178-4187, Des 2010, doi: 10.1109/TIE.2010.2043035.

[2] D. Saji, P. S. Babu, dan K. Ilango, "SoC Estimation of Lithium Ion Battery Using Combined Coulomb Counting and Fuzzy Logic Method," dalam 2019 4th International Conference on Recent Trends on Electronics, Information, Communication \& Technology (RTEICT), Bangalore, India, Mei 2019, hlm. 948-952. doi: 10.1109/RTEICT46194.2019.9016956.

[3] D. W. Hart, Power electronics. New York: McGraw-Hill, 2011.

[4] D. Ounnas, D. Guiza, Y. Soufi, R. Dhaouadi, dan A. Bouden, "Design and Implementation of a Digital PID Controller for DC-DC Buck Converter," dalam 2019 1st International Conference on Sustainable Renewable Energy Systems and Applications (ICSRESA), Tebessa, Algeria, Des 2019, hlm. 1-4. doi: 10.1109/ICSRESA49121.2019.9182430.

[5] I. N. W. Satiawan dan I. B. F. Citarsa, "DESAIN BUCK CONVERTER UNTUK CHARGING BATERE PADA BEBAN BERVARIASI," hlm. 6.

[6] D. Renwal dan M. Kumar, "Hybrid PI-fuzzy logic controller based DC-DC converter," dalam 2015 International Conference on Green Computing and Internet of Things (ICGCIoT), Greater Noida, Delhi, India, Okt 2015, hlm. 753-757. doi: 10.1109/ICGCIoT.2015.7380563.

[7] G. Dewantoro, D. Susilo, dan P. P. Adi, "Implementasi Pengendali Logika Fuzzy pada Navigasi Robot Penjejak Dinding," JTE, vol. 16, no. 2, hlm. 72, Agu 2017, doi: 10.24843/MITE.2017.v16i02p13.

[8] S. N. Soheli, G. Sarowar, Md. A. Hoque, dan M. S. Hasan, "Design and Analysis of a DC -DC Buck Boost Converter to Achieve High Efficiency and Low Voltage Gain by using Buck Boost Topology into Buck Topology," dalam 2018 International Conference on Advancement in Electrical and Electronic Engineering (ICAEEE), Gazipur, Bangladesh, Nov 2018, hlm. 1-4. doi: 10.1109/ICAEEE.2018.8643001.

[9] M. W. Alim, N. A. Windarko, dan R. Rakhmawati, "Fuzzy Logic Control Design On Buck Converter For Thermo Electric Air Cooler Power Supply," JAREE, vol. 4, no. 2, Okt 2020, doi: 10.12962/j25796216.v4.i2.137.

[10] A. Ilyas, S. Jahan, dan M. Ayyub, "Tuning Of Conventional Pid And Fuzzy Logic Controller Using Different Defuzzification Techniques," vol. 2, no. 1, hlm. 5, 2013. 